\title{
Isolation of an N-alkylated Benzylamine Derivative from Pseudomonas putida BTP1 as Elicitor of Induced Systemic Resistance in Bean
}

\author{
Marc Ongena, ${ }^{1}$ Emmanuel Jourdan, ${ }^{1}$ Mathias Schäfer, ${ }^{2}$ Cécile Kech, ${ }^{3}$ Herbert Budzikiewicz, ${ }^{2}$ \\ André Luxen, ${ }^{3}$ and Philippe Thonart ${ }^{1}$ \\ ${ }^{1}$ Centre Wallon de Biologie Industrielle, Service de Technologie Microbienne, University of Liège, B-4000 Liège and Unité \\ de Bioindustries, Gembloux Agricultural University, B-5030 Gembloux, Belgium; ${ }^{2}$ Institüt für Organische Chemie, University \\ of Cologne, 50939 Köln, Germany; ${ }^{3}$ Unité de Chimie Organique de Synthèse, University of Liège, B-4000 Liège, Belgium
}

Submitted 13 December 2004. Accepted 11 February 2005.

\begin{abstract}
Root treatment of Phaseolus vulgaris with the nonpathogenic Pseudomonas putida BTP1 led to significant reduction of the disease caused by the pathogen Botrytis cinerea on leaves. The molecular determinant of $P$. putida BTP1 mainly responsible for the induced systemic resistance (ISR) was isolated from cell-free culture fluid after growth of the strain in the iron-poor casamino acid medium. Mass spectrometry analyses performed on both the bacterial product and synthetic analogues revealed a polyalkylated benzylamine structure, with the quaternary ammonium substituted by methyl, ethyl, and $C_{13}$ aliphatic groups responsible for the relative hydrophobicity of the molecule. The specific involvement of the $\mathrm{N}$-alkylated benzylamine derivative (NABD) in ISR elicitation was first evidenced by testing the purified compound that mimicked the protective effect afforded by crude supernatant samples. The evidence was supported by the loss of elicitor activity of mutants impaired in NABD biosynthesis. Our experiments also showed that other iron-regulated metabolites secreted by the strain are not involved in ISR stimulation. Thus, these results indicate a wider variety of Pseudomonas determinants for ISR than reported to date.
\end{abstract}

Additional keywords: biological control, plant growth-promoting rhizobacteria.

Among the biological control alternatives to the use of chemical pesticides, the application of nonpathogenic soil bacteria living in association with plant roots is of increasing interest (Walsh et al. 2001; Zahir et al. 2004). In many cases, treatment with some of these plant growth-promoting rhizobacteria (PGPR) was associated with reduced plant diseases in greenhouse and field experiments. PGPR can exert their beneficial effect on plants by inhibiting pathogen growth via several mechanisms, such as niche exclusion, competition for nutrients, siderophore-mediated competition for iron, synthesis of antibiotics, and production of extracellular enzymes (Haas and Keel 2003; Ramamoorthy et al. 2001; Whipps 2001). The isolation of some rhizobacteria lacking the ability to exert any direct antagonistic activity toward pathogens sheds new light on the diversity of their modes of action and suggested that such strains may activate host defense systems (Van Loon et al.

Corresponding author: M. Ongena; Telephone: ++32-4-366-2861; Fax: ++32-4-366-2862; E-mail: ongena.m@ fsagx.ac.be
1998). Because bacterial treatment at the root level confers durable protection against foliar or systemic pathogens, the PGPRmediated resistance is phenotypically similar to the well-studied systemic acquired resistance (SAR) activated after a first infection by an incompatible necrotizing pathogen (Durrant and Dong 2004; Sticher et al. 1997). This effect of rhizobacteria is referred to as induced systemic resistance (ISR) (Kloepper et al. 1992). ISR is effective against a broad range of fungal, bacterial, and viral diseases, as well as against some insect and nematode pests, and ISR-based disease control assays were performed successfully under field conditions (Wei et al. 1996; Zehnder et al. 2001).

Until recently, PGPR determinants responsible for ISR elicitation could be divided into two classes: cell surface components, such as flagella or outer membrane lipopolysaccharides, and iron-regulated metabolites with siderophore activity (Van Loon et al. 1998). The elicitor activity of lipopolysaccharides or, more specifically, of their O-antigenic side chain, was identified for Pseudomonas fluorescens on carnation (Van Peer and Schippers 1992), radish (Leeman et al. 1995), and tomato (Duijff et al. 1997) and also for Rhizobium etli on potato (Reitz et al. 2002). The composition of lipopolysaccharides from pseudomonads is strain specific and their eliciting activity seems to be dependent on the isolate. Pyoverdines typically synthesized by fluorescent Pseudomonas spp. (Budzikiewicz 2004) were suggested as siderophore-type ISR elicitors. In soil, efficient production of pyoverdines with very high affinity for ferric ions can restrict fungal pathogen growth and thereby limit disease incidence by making this element unavailable (Loper and Buyer 1991). From experiments involving pyoverdine-nonproducing mutants (Maurhofer et al. 1994) or addition of pure pyoverdines (Leeman et al. 1996), these compounds also were suggested as potential ISR elicitors; however, this hypothesis is controversial and probably cannot be applied commonly to other Pseudomonas strains (Van Loon et al. 1998). Investigations conducted by Press and associates (2001) suggest that the expression of genes involved in the biosynthesis of an unidentified catechol siderophore is associated with ISR induced by Serratia marcescens 90-166 in cucumber. Salicylic acid (SA) is produced by some of the rhizobacteria that induce systemic resistance under iron-limited conditions. Its role in the ISR elicitation process was demonstrated in the case of Pseudomonas aeruginosa KMPCH (De Meyer et al. 1997, 1999) and P. fluorescens P3, which was converted to an ISR-inducing strain by the insertion of SA biosynthetic genes (Maurhofer et al. 1998). Nevertheless, several 
reports showed that SA production by other strains was not associated with ISR (Leeman et al. 1996; Press et al. 1997). $\mathrm{SA}$ is also a precursor or intermediate in the biosynthesis of other siderophores, such as pyochelin in $P$. aeruginosa (Serino et al. 1997) or pseudomonine produced by $P$. fluorescens (Mercado-Blanco et al. 2001). No ISR-eliciting activity was clearly demonstrated for the latter compound; however, a role for pyochelin acting synergistically with the phenazine pyocyanine was reported for ISR triggered in tomato by $P$. aeruginosa 7NSK2 (Audenaert et al. 2002). Another antibiotic from Pseudomonas spp., 2,4-diacetylphloroglucinol (DAPG), also retains some ability to stimulate defense-related reactions in the host plant (Lavicoli et al. 2003). In general, the mechanisms involved in rhizobacteria-mediated ISR appear to vary among bacterial strains or pathosystems and much remains to be discovered about the nature and variety of bacterial determinants responsible for the elicitation of defense mechanisms.

We previously have reported the ISR-mediated protective effect of $P$. putida BTP1 on cucumber against root rot caused by Pythium aphanidermatum (Ongena et al. 1999, 2000). The strain also was effective at reducing disease incidence caused by Botrytis cinerea on bean plants (Ongena et al. 2002). Most of the resistance-eliciting activity of the strain was retained in a specific fraction of the supernatant extract obtained after growth in an iron-limited medium. The objective of the current study was to identify the specific agent to which systemic resistance-inducing activity can be attributed.

\section{RESULTS}

\section{Isolation of the ISR determinant}

from Pseudomonas putida BTP1.

In a previous study, we showed that the ISR-eliciting potential of Pseudomonas putida BTP1 was retained mostly by hydrophobic material secreted in the medium upon growth of the strain in the iron-poor casamino acids medium (CAA) (Ongena et al. 2002). The active ingredient was purified as described below (discussed below) to the single peak in the high-performance liquid chromatography (HPLC) profile (Fig. 1). When tested at a concentration of $0.2 \mu \mathrm{M}$ in the nutrient solution, the compound induced a $24 \%$ reduction in the number of spreading lesions caused by the leaf pathogen $B$. cinerea on hydroponically grown bean plants (Fig. 2). This protection level was similar to the level observed by testing crude supernatant samples (28\%) diluted in a way to add the elicitor at the same final concentration in contact with the roots. Treatment of bean roots with a 10-fold higher concentration of the elicitor did not result in enhanced disease biocontrol level and no protection was provided by applying the elicitor at a concentration as low as $2 \mathrm{nM}$ (data not shown). The material eluted before and after the elicitor during HPLC purification was concentrated and also tested as a single sample. No marked re-

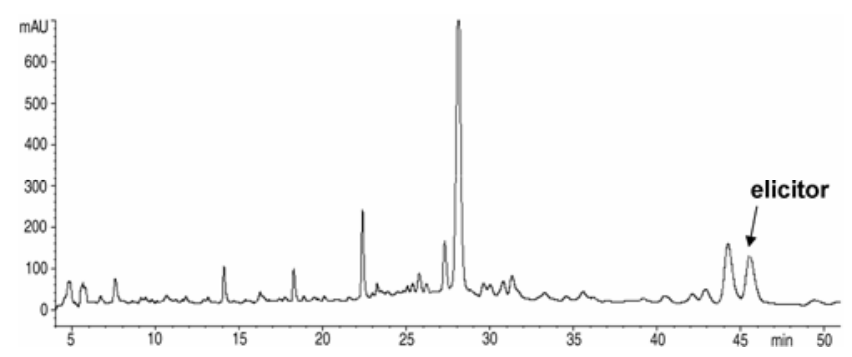

Fig. 1. Typical chromatogram obtained for the purification/analysis of the elicitor produced by Pseudomonas putida BTP1 by reverse-phase highperformance liquid chromatography from casamino acids medium supernatant extract. sistance was induced in bean by this treatment (data not shown). Upon addition of ferric chloride to the CAA medium at final concentrations of 100 and $200 \mu \mathrm{M}$, production of the elicitor by BTP1 was reduced to values of $1.9 \pm 0.28$ and $0.7 \pm$ $0.15 \mathrm{ng} / 10^{8} \mathrm{CFU}$, respectively; whereas, without ferric chloride, BTP1 produced $75.5 \pm 10.1 \mathrm{ng} / 10^{8} \mathrm{CFU}$ of elicitor. None of the resulting culture supernatant extracts, after addition of ferric chloride, showed resistance-inducing activity (Fig. 2).

\section{ISR activity of mutants from $P$. putida BTP1.}

Additional evidence for the ISR-eliciting potential of the active fraction arose from the evaluation of protective levels triggered by treatment of bean with BTP1 derivatives obtained by chemical mutagenesis. The two mutants designated as M3 and M1 originally were selected for their reductions in pyoverdine biosynthesis. The growth of both M1 and M3 is also markedly reduced in iron-restricted media (King's B medium [KB] or CAA supplemented with the chelating agent ethylenediamine-di-(o-hydroxyphenylacetate [EDDHA]) compared with the wild-type BTP1 and fully restored in iron-rich media (data not shown), suggesting that growth of M1 and M3 are reduced when pyoverdines are necessary to supply the cells with iron. Although pyoverdine synthesis is repressed in both isolates, M3 is still effective at producing the ISR determinant at a level similar to BTP1 (Table 1). ISR experiments performed in soil with live cells revealed a complete loss of the protective activity by the M1 derivative. At the same time, M3 retained the ability to induce ISR (Table 1). Bacterial concentrations in the rhizosphere were estimated at $4.6 \pm 2.5$ and $7.2 \pm 2.2 \times 10^{5}$ $\mathrm{CFU} / \mathrm{g}$ of root fresh weight for M1 and M3, respectively. Mutant cells were not detected in leaf samples with a detection

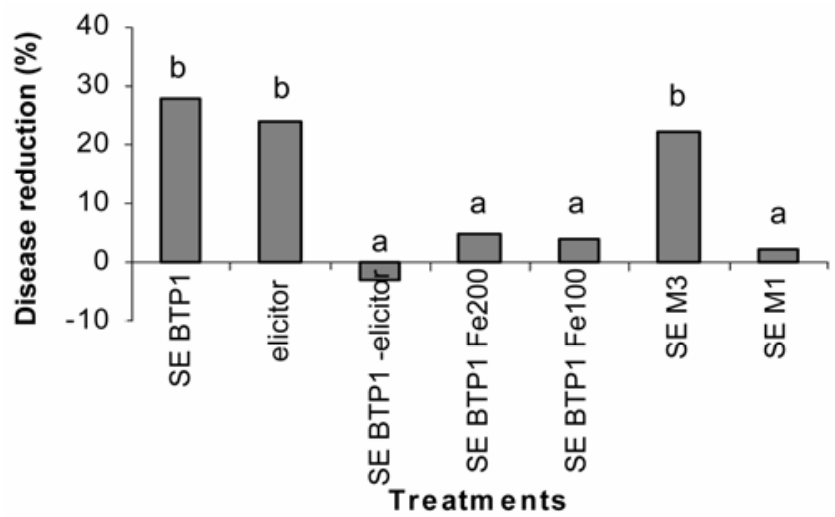

Fig. 2. Resistance induced in bean plants by the purified elicitor or by various culture extracts from Pseudomonas putida BTP1 or its derivatives. Treatments are as follows: ethyl acetate extracts of supernatants (SE) obtained after growth of BTP1, M1, and M3 (SE BTP1, SE M1, and SE M3, respectively) in casamino acids medium (CAA). These extracts containing the elicitor were added to the nutrient solution to obtain a $0.2-\mu \mathrm{M}$ final concentration of the active compound; SE BTP1-elicitor, supernatant sample corresponding to the SE BTP1 extract but without semi-preparative high-performance liquid chromatography fractions containing the elicitor; elicitor, active compound tested in a pure form at a concentration of 0.2 $\mu \mathrm{M}$; SE BTP1 Fe200 and SE BTP1 Fe100, ethyl acetate extract of supernatant obtained after growth of BTP1 in CAA supplemented with $\mathrm{FeCl}_{3}$ at final concentrations of 200 and $100 \mu \mathrm{M}$. The reduction in the number of Botrytis cinerea spreading lesions is relative to the number of lesions counted in control plants. Data are means of three independent experiments except for assays with SE BTP1 Fe200 and SE BTP1 Fe100 treatments that were performed twice. The homogeneity of variances was tested by analysis of variance and data from experiments with the same set-up were pooled for analysis because interactions between experiment and treatment were not significant at $P=0.05$. Means from the different treatments were compared by the method of Newman and Keuls (least significant difference at $\alpha=0.05$ ). Values indicated with "a" are not statistically different from the control. 
limit of approximately $100 \mathrm{CFU} / \mathrm{g}$ of leaf, suggesting that bacteria did not migrate through the plants.

The different ISR-eliciting potential of M1 and M3 was examined further by comparing the activity of the corresponding supernatant extracts obtained after their growth in the CAA medium. Crude elicitor extracts from M3 resulted in an enhanced resistance of bean plants to $B$. cinerea; extracts prepared from the M1 culture failed to confer resistance (Fig. 2). Other than the strong reduction of peaks corresponding to pyoverdine and ISR elicitor (in the case of M1), no significant change was observed in HPLC profiles upon analysis of 10fold concentrated culture supernatant of M1 or M3 compared with BTP1 (detection at 214, 280, and $375 \mathrm{~nm}$; data not shown).

\section{Structural characterization of the ISR determinant.}

Electrospray ionization-mass spectrometry (ESI-MS) analysis of the active fraction showed two molecular ions at $\mathrm{m} / \mathrm{z}$ 304.301 and 332.332 (as determined by exact mass measurements), corresponding to $\mathrm{C}_{21} \mathrm{H}_{38} \mathrm{~N}$ (calculated 304.3004) and $\mathrm{C}_{23} \mathrm{H}_{42} \mathrm{~N}$ (calculated 332.3317), respectively (Fig. 3A). Analysis of a solution of the material in $\mathrm{CH}_{3} \mathrm{OD}$ revealed no mass change of the molecular ions, indicating the absence of exchangeable protons. Further structural information was obtained by collision-induced fragmentation of the molecular ions in the octapole and the ion trap region of the mass spectrometer. From the major component with $\mathrm{M}^{+} \mathrm{m} / \mathrm{z} 332$ in the octapole region, three fragments are obtained: $\mathrm{m} / \mathrm{z} 91$, characteristic for a benzyl group responsible for the UV absorption peak at $276 \mathrm{~nm} ; \mathrm{m} / \mathrm{z} 240$ (i.e., $[\mathrm{M}-92]^{+}$); and m/z 58 (Fig. $3 B$ ). Fragmentation in the ion trap gave only $\mathrm{m} / \mathrm{z} 240$. Subsequent collision activation (CA) fragmentation of the selected $\mathrm{m} / \mathrm{z} 240$ in the ion trap (Fig. 3C) gave m/z 72 as most abundant fragment, and a series of alkenyl ions, m/z 69, 83, 97, 111 , and 125 , indicating the presence of an alkyl chain. CA fragmentation of the component with $\mathrm{M}^{+} \mathrm{m} / \mathrm{z} 304$ gave the same pattern, indicating that the structural difference lay only in the length of the alkyl chain (two $\mathrm{CH}_{2}$ groups shorter).

Tentative structures for the major compound can be proposed from the fragmentation analysis (Fig. 4). Based on the method described by Salvatore and associates (2002), structural analogues were chemically synthesized by successive $\mathrm{N}$ alkylation of commercial phenethylamine or benzylamine and a final acido-basic reaction yielding a methylated product. MS spectra of the model compounds (Fig. 4A and B) were compared with the microbial product. The formation of $\mathrm{m} / \mathrm{z} 91$ and the loss of $92 \mathrm{u}$ suggest that the benzyl group is connected to $\mathrm{N}$

Table 1. Quantification of elicitor and pyoverdine produced by Pseudomonas putida BTP1 and two derivatives in relation with resistance induced in bean plants

\begin{tabular}{lccc}
\hline Isolate & $\begin{array}{c}\text { Pyoverdine } \\
\left(\boldsymbol{\mu g} / \mathbf{1 0}^{\mathbf{8}} \mathbf{C F U}\right)^{\mathbf{y}}\end{array}$ & $\begin{array}{c}\text { Elicitor } \\
\left(\mathbf{n g} / \mathbf{1 0}^{\mathbf{8}} \mathbf{C F U}\right)^{\mathbf{y}}\end{array}$ & $\begin{array}{c}\text { Disease reduction } \\
\mathbf{( \% )}^{\mathbf{z}}\end{array}$ \\
\hline BTP1 & $21.2 \pm 4.53$ & $70.3 \pm 14$ & $39 \mathrm{~b}$ \\
M3 & $4.1 \pm 2.21$ & $62.8 \pm 8.4$ & $32 \mathrm{~b}$ \\
M1 & $1.2 \pm 0.17$ & $7.9 \pm 3.1$ & $6 \mathrm{a}$ \\
\hline
\end{tabular}

${ }^{\mathrm{y}}$ Data obtained from 72 -h growth of the isolates in casamino acids medium. Each value is the mean of five repetitions.

${ }^{\mathrm{z}}$ Expressed as the reduction in Botrytis cinerea spreading lesions relative to the number of spreading lesions in control plants treated with sterile distilled water. Data are means of two independent experiments. The homogeneity of variances was tested by analysis of variance and data from experiments with the same set-up were pooled for analysis because interactions between experiment and treatment were not significant at $P=$ 0.05 . Means from the different treatments were compared by the method of Newman and Keuls (least significant difference at $\alpha=0.05$ ). Values followed by "a" are not statistically different from the control.
$\left(\mathrm{C}_{6} \mathrm{H}_{5}-\mathrm{CH}_{2}-\mathrm{N}\right)$ because Figure $4 \mathrm{~A}$ upon $\mathrm{CA}$ gives $\mathrm{m} / \mathrm{z} 105$ $\left(\mathrm{C}_{6} \mathrm{H}_{5}-\mathrm{CH}_{2} \mathrm{CH}_{2}\right)$, whereas Figure $4 \mathrm{~B}$ gives $\mathrm{m} / \mathrm{z} 91$. The formation of $\mathrm{m} / \mathrm{z} 58\left(\mathrm{C}_{3} \mathrm{H}_{8} \mathrm{~N}\right)$ and $\mathrm{m} / \mathrm{z} 72\left(\mathrm{C}_{4} \mathrm{H}_{10} \mathrm{~N}\right)$ products could be explained by the typical amine fragmentations according to the scheme represented in Figure 5. From these results, the structure $\mathrm{M}^{+}$represented was established for the elicitor that we named $\mathrm{N}$-alkylated benzylamine derivative (NABD).

\section{DISCUSSION}

This work describes the isolation and identification of a metabolite secreted by $P$. putida BTP1 that is specifically involved in the induction of systemic resistance in bean against leaf infection by $B$. cinerea. The elicitor properties were established on the basis of the following observations: i) treatment of bean roots with the pure compound NABD mimicked the protective effect of crude culture supernatant, ii) NABD-depleted culture broth did not induce resistance, iii) addition of $\mathrm{Fe}^{3+}$ to the medium led to a loss of ISR-eliciting activity and NABD production, iv) the ISR determinant did not inhibit the growth of the pathogen at the concentrations tested in the ISR assays (data not shown), and v) a BTP1 derivative M1 with reduced NABD synthesis also was impaired in its efficacy to stimulate ISR. Despite a strongly reduced pyoverdine production rate, this mutant and the other one used in this study (M3) retain some root-colonizing ability to a level that should be sufficient to trigger ISR (Raaijmakers et al. 1995). On the other hand, previous in vitro antagonism assays revealed that both $P$. putida BTP1 and the mutant M3 do not produce any antifungal compound (Ongena et al. 1999). We also have verified that strain M1 did not inhibit mycelial growth of Pythium aphanidermatum, Fusarium oxysporum, or B. cinerea on any of the media tested (M. Ongena, unpublished results). Thus, M1 and M3 seemingly are not affected in the production of other metabolic products that could be specifically involved in biocontrol, such as antibiotics or other ISR elicitors, compared with the wild type.

Further research is required to determine the mechanism of ISR induction by NABD. The specific accumulation of antifungal compounds has been observed in infected leaves following treatment with NABD (M. Ongena, unpublished results). Additional investigations are required to identify these fungitoxic plant metabolites; however, ISR stimulation by NABD may be related to phytoalexin accumulation, an important defense mechanism involved in the pathogen-induced SAR (Hammerschmidt 1999). Increased protection by BTP1 already was associated with the stimulation of a systemic response based on the accumulation of antifungal compounds in cucumber (Ongena et al. 2000) and tomato (M. Ongena, E. Jourdan, A. Giger, and P. Thonart, unpublished results). Thus, NABD produced by strain BTP1 may be active on different plant species for the control of diseases caused by various pathogens.

Other Pseudomonas metabolites previously reported as ISR elicitors obviously are not involved in the beneficial effect triggered by BTP1. The strain has developed an efficient pyoverdine-mediated iron acquisition system (Jacques et al. 1995; Ongena et al. 2001); however, these chromopeptides do not play any role because previous results showed that pyoverdineenriched extracts failed to induce resistance (Ongena et al. 2002). Moreover, ISR assays from this study revealed that the BTP1 derivative M3 strongly repressed in pyoverdine synthesis; however, with conserved elicitor production, it still retained almost all the protective effect developed by the wild type. In experiments performed on cucumber with the same strain, several lines of evidence also indicated that pyoverdines had little influence on the protective properties of BTP1 related to plant defense induction (Ongena et al. 1999). SA production by strain BTP1 is much lower than that observed for PGPR (considered to 
be efficient producers), and its methyl ester form or pyochelin were not detected after growth of the strain in appropriate medium. Moreover, heat-killed BTP1 cells were fully impaired in providing any protective effect in the same pathosystem, suggesting that no heat-stable cell-envelop components, such as lipopolysaccharides, play a major role in the ISR elicitation process (Ongena et al. 2002). Recent studies have shown that some bacterial products such as pyocyanine and 2,4-diace- tylphloroglucinol, which are known for their antibiotic activities, also retain some ability to stimulate defense-related reactions in the host plant (Audenaert et al. 2002; Lavicoli et al. 2003). However, we already reported that BTP1 could not inhibit pathogen growth and did not produce or excrete any fungitoxic compounds either in vitro on several media or upon growth on roots (Ongena et al. 1999). Thus, ISR induction by the strain is unlikely to be related to the production of any antibiotic mole-

A

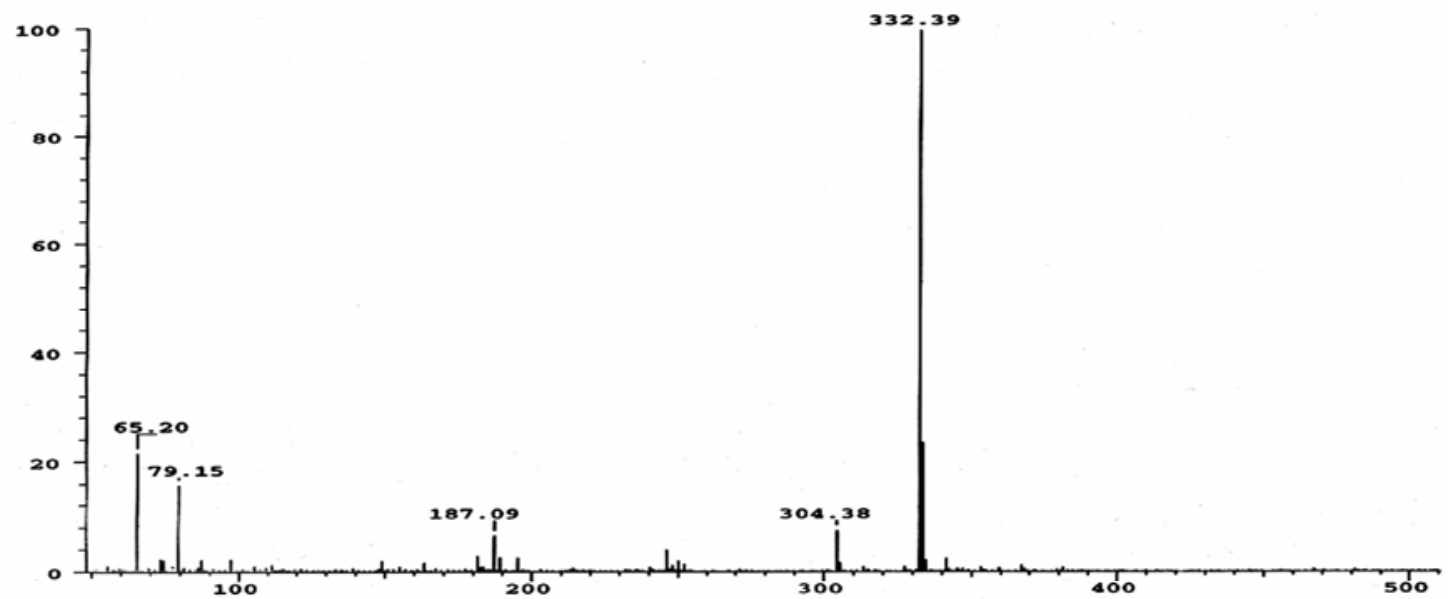

B

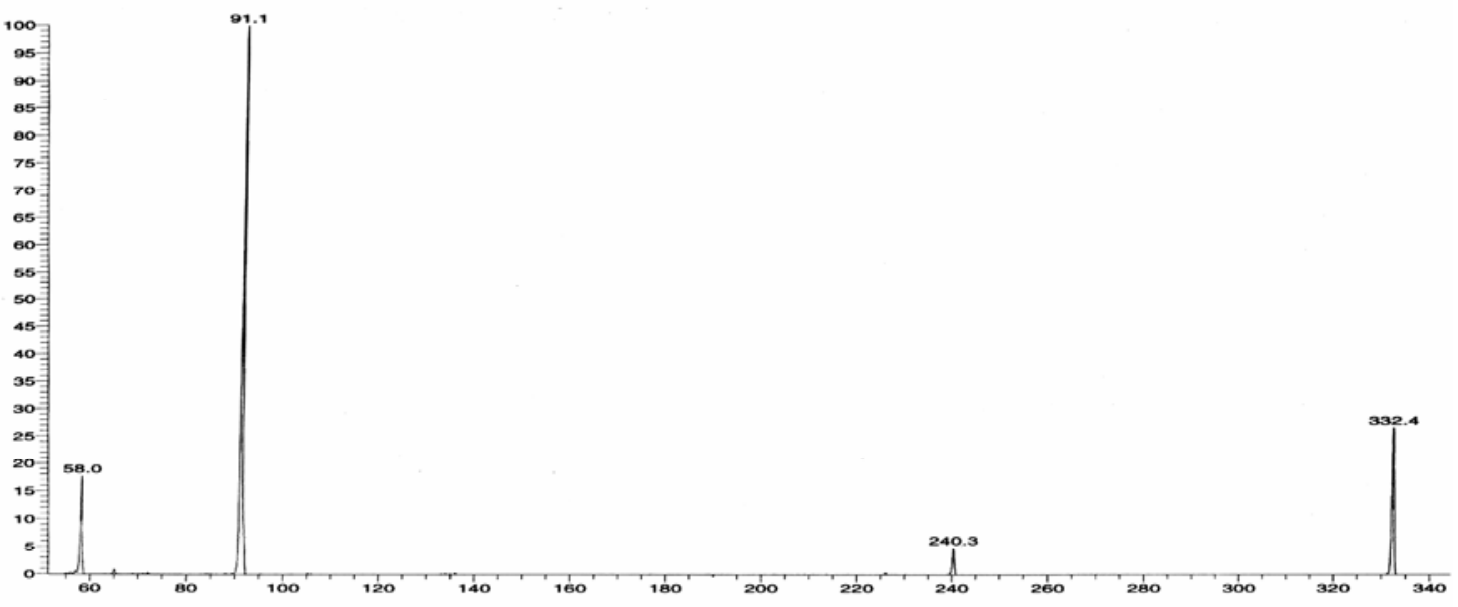

C

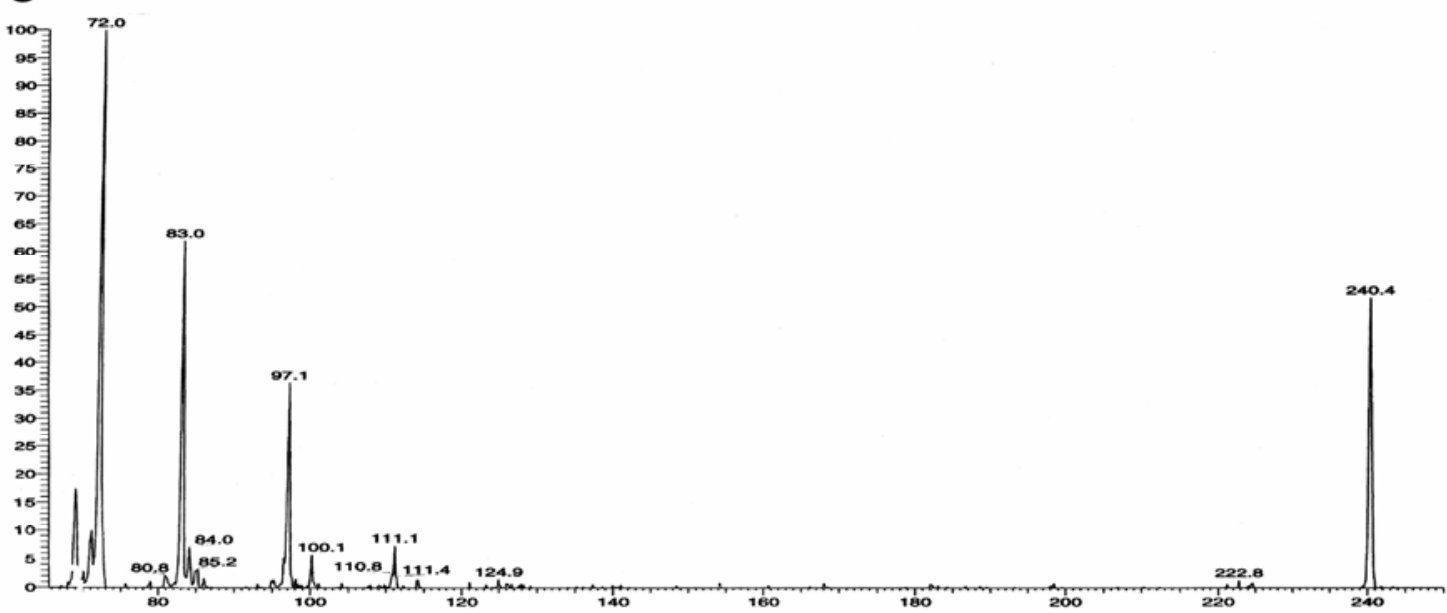

Fig. 3. A, Electrospray ionization-mass spectrometry analysis spectrum obtained for the analysis of the pure induced systemic resistance determinant from Pseudomonas putida BTP1. B, Ion trap octapole collision activation (CA)-spectrum of the molecular ion at $\mathrm{m} / \mathrm{z} 332.4$. C, CA-spectrum of the main ion at $\mathrm{m} / \mathrm{z} 240.3$ generated upon fragmentation of the molecular ion. 
cule with plant defense-stimulating activity. All these observations strongly suggest that NABD isolated in this work retains most of the elicitor activity among the metabolites produced by the strain.

In situ detection of active metabolites produced by biocontrol bacteria has been described as a strategy that complements the indirect evidence provided by other approaches about their specific involvement in the protective effect developed by the strain. Several attempts were made to detect the eliciting compound in the rhizosphere of bean plants treated with BTP1. Results were highly variable; however, in two independent experiments, amounts of 5 to $8 \mathrm{ng} / \mathrm{g}$ of root fresh weight were measured, suggesting an efficient production of the elicitor by the bacterium growing on roots. This concentration is in the range of production levels observed in situ for other ISR-eliciting compounds, such as SA (Audenaert et al. 2002; De Meyer et al. 1999; Maurhofer et al. 1998), and for a wide variety of antibiotics involved in the biocontrol of soil diseases provided by other fluorescent pseudomonads (Raaijmakers et al. 2002). Although it does not address the question of whether the amount of elicitor is sufficient to activate the plant in situ, it suggests that NABD production by BTP1 has occurred in its ecological niche.

From a structural point of view, biological compounds with plant defense-eliciting properties vary widely in nature. They may be surface components such as $\beta$-glucans, chitin-derived oligomers, or pectin fragments; oligogalacturonides released from the fungal pathogen or the host plant, or flagellin- or glycine-rich proteins; peptides such as syringolin isolated from bac-

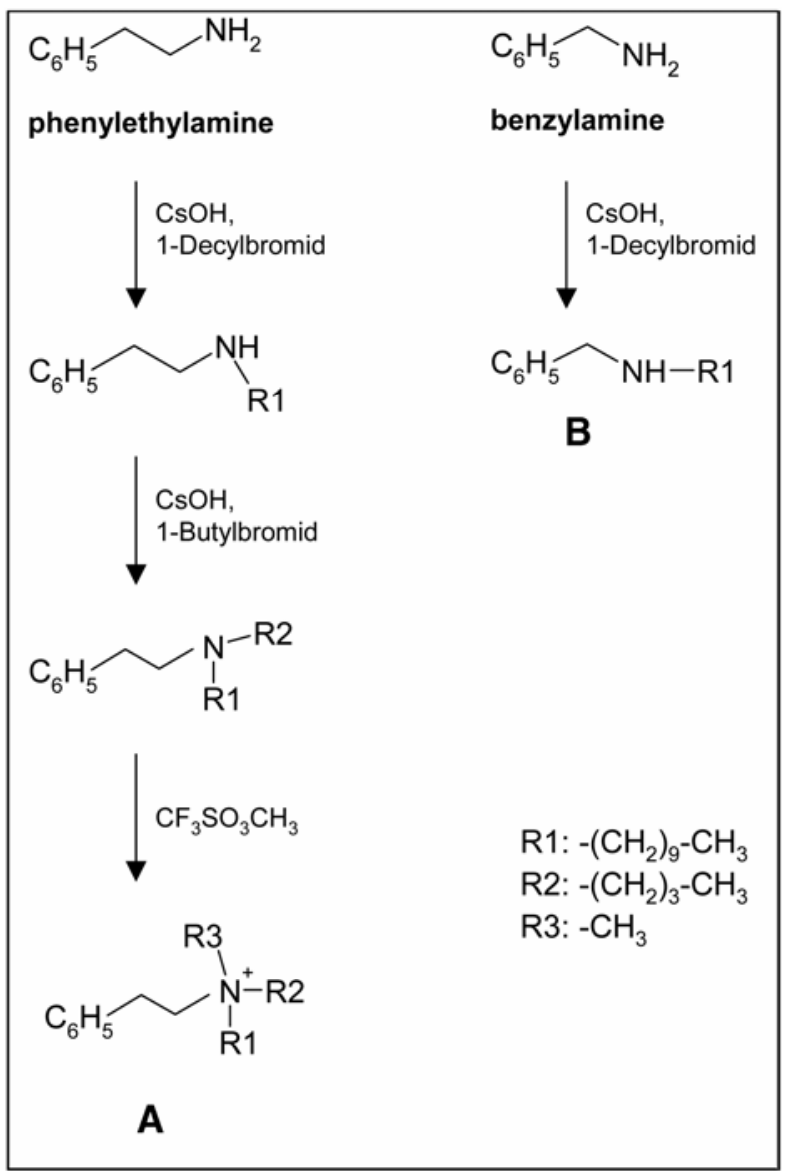

Fig. 4. Organic synthesis of the quaternary ammonium starting from phenylethylamine (a) and of the mono $\mathrm{N}$-alkyl intermediate starting from benzylamine (b). It involves the formation of $\mathrm{N}$-decyl and $\mathrm{N}$-decyl- $\mathrm{N}$-butyl intermediates via two chemoselective reactions catalyzed by $\mathrm{CsOH}$ and a last acido-basic reaction yielding the final methylated product. terial pathogens; unsaturated fatty acids; or volatiles produced by B. subtilis (Ebel and Mithöfer 1998; Fliegmann et al. 2003; Klarzynski et al. 2003; Kuć 2001; Nürnberger and Scheel 2001; Ryu et al. 2004; Tanaka et al. 2003; Waspï et al. 1998). Certain synthetic chemicals, such as 2,6-dichloro isonicotinic acid, benzothiadiazole and its derivative acibenzolar-S-methyl, or $\beta$ amino butyric acid, also can be very effective in the induction of SAR when applied to plants (Ostendorp et al. 2001). However, none of these compounds is structurally related to NABD produced by BTP1. The ISR determinant synthesized by BTP1 consists of a benzylamine moiety with the quaternary ammonium substituted by methyl, ethyl, and the long C13 alkyl groups responsible for the relative hydrophobicity of the molecule. Phenyl-derived amines belong to the group of biogenic amines which might be produced by bacteria following decarboxylation of free amino acids (Silla Santos 1996). However, to our knowledge, a compound with the structure established for ISR elicitor synthesized by BTP1 hitherto has not been described among Pseudomonas products. Forthcoming work will be devoted to the identification of biosynthesis genes and the study of environmental factors and intracellular pathways regulating NABD production. In parallel, chemical synthesis of various structural analogues will allow evaluation of critical features essential for the ISR-eliciting activity.

\section{MATERIALS AND METHODS}

\section{Microbial strains.}

Pseudomonas putida BTP1, isolated from barley roots, originally was selected for its specific features regarding pyoverdinemediated iron transport (Jacques et al. 1995; Ongena et al. 2001). All strains were maintained on Pseudomonas agar $\mathrm{F}$ medium (KB; Becton, Dickinson, and Company, Le pont de Claix, France) at $4^{\circ} \mathrm{C}$ before experimental use, and stored at $80^{\circ} \mathrm{C}$ in cryotubes according to the manufacturer's recommendations (Microbank; Prolab Diagnostic, Richmond Hill, Canada) for long-term conservation. The fungal pathogen $B$. cinerea was provided by M. Höfte (Ghent University) (De Meyer et al. 1997). B. cinerea was routinely grown to sporulation on an oatbased medium (oatmeal, $25 \mathrm{~g} /$ liter; agar, $12 \mathrm{~g} / \mathrm{liter}$ ) at room temperature. For long-term storage, spores were conserved in $40 \%$ glycerol at $-70^{\circ} \mathrm{C}$.

\section{Isolation and characterization of chemical mutants.}

Mutants M1 and M3 were obtained from BTP1 after chemical mutagenesis with $N$-methyl-N'-nitro- $N$-nitrosoguanidine (NTG) following a procedure described previously (Ongena et al. 1999). Briefly, the chemical mutagen was added to exponentially growing cells for $15 \mathrm{~min}$ under constant agitation. After washing and dilution, cell suspensions were plated onto chrome azurol S agar medium (CAS) and incubated at $30^{\circ} \mathrm{C}$ for $48 \mathrm{~h}$. Out of approximately 2,500 colonies, 21 isolates were selected for their inability to discolor CAS and, thus, for their siderophore-negative phenotype. M1 and M3 then were selected from this short library on the basis of their different phenotypes regarding ISR elicitor production, which was evaluated after growth in CAA (Cornélis et al. 1992) as described below.

The two mutants were further examined for several traits. In vitro growth of M1 and M3 were compared with the wild type in liquid media with various iron content: LB (caseine hydrolysate at $10 \mathrm{~g} \mathrm{liter}^{-1}$, yeast extract at $5 \mathrm{~g} \mathrm{liter}^{-1}$, and $\mathrm{NaCl}$ at $5 \mathrm{~g}$ liter $^{-1}$ ), CAA medium, CAA + EDDHA at $300 \mathrm{mg} \mathrm{liter}^{-1}$, CAA + $\mathrm{FeCl}_{3} \cdot 6 \mathrm{H}_{2} \mathrm{O}$ at $1 \mathrm{~g}$ liter-1, $\mathrm{KB}$ medium, and $\mathrm{KB}+\mathrm{FeCl}_{3} \cdot 6 \mathrm{H}_{2} \mathrm{O}$ at $1 \mathrm{~g} \mathrm{liter}^{-1}$. Flasks were incubated under agitation $(150 \mathrm{rpm})$ at $30^{\circ} \mathrm{C}$ for $48 \mathrm{~h}$. Biomass concentration and pyoverdine production rates were determined spectrophotometrically as described below. The production of SA was tested by using the method 
reported by Ongena and associates (2002). Mutant M1 also was tested on various media for its ability to inhibit the growth of some phytopathogens in petri plates by following the method described by Ongena and associates (1999) for BTP1 and M3.

Root colonization by mutants was evaluated on 20-day-old plants. Root samples $(1 \mathrm{~g})$ were collected randomly from three plants in two independent experiments. They were washed briefly with sterile distilled water to remove most of the soil. They were homogenized in $10 \mathrm{ml}$ of sterile peptone water (bacto-peptone at $1 \mathrm{~g} / \mathrm{liter}, \mathrm{NaCl}$ at $9 \mathrm{~g} / \mathrm{liter}$, and $0.02 \%$ [vol/vol] Tween 80$)$ and $1 \mathrm{~g}$ of glass beads $(0.18 \mathrm{~mm}$ in diameter). Serial dilutions were plated on King's B medium and counts of M1 and M3 colonies were made after $24 \mathrm{~h}$ of incubation at $30^{\circ} \mathrm{C}$ on the basis of their typical morphology (white, smooth, and viscous).

\section{Elicitor purification.}

P. putida BTP1 was grown in 3-liter Erlenmeyer flasks (agitated at $150 \mathrm{rpm}$ ) containing 1.5 liters of CAA medium for $72 \mathrm{~h}$ at $30^{\circ} \mathrm{C}$. Cells were eliminated by centrifugation at $13,500 \times g$ for $15 \mathrm{~min}$. The lyophilized supernatant was dissolved in distilled water (150-fold concentrated), adjusted to $\mathrm{pH} 6$ with 0.1 $\mathrm{M} \mathrm{HCl}$, and extracted three times with a doubled volume of ethyl acetate. The organic phase containing the elicitor was evaporated to dryness under vacuum and the residue was solubilized in $10 \% \mathrm{MeOH}$. This solution $(15 \mathrm{ml})$ was applied to an Alltech C18 SPE column (Alltech Associates, Inc., Lokeren, Belgium) (10 g) previously activated by washing with $20 \mathrm{ml}$ of methanol and $20 \mathrm{ml}$ of acetonitrile (ACN) and equilibrated with $40 \mathrm{ml}$ of MilliQ water. The column was extensively washed with water $(80 \mathrm{ml})$ to remove nonadsorbed material and successively rinsed with $20 \mathrm{ml}$ of 20,40 , and $60 \%$ ACN to eliminate contaminating compounds that were moderately fixed to the matrix. The elicitor was eluted from the cartridge with $20 \mathrm{ml}$ of $80 \%$ $\mathrm{ACN}$ and the corresponding fraction was lyophilized. The residue was dissolved in $1 \mathrm{ml}$ of $100 \% \mathrm{MeOH}$ and the elicitor further purified by reverse-phase HPLC (Hewlett-Packard 1100 series apparatus). Repeated injections of $100-\mu l$ aliquots of the methanolic extract were realized on a semi-preparative Chromspher 5 C-18 column (250 by $10 \mathrm{~mm}, 5-\mu \mathrm{m}$ packing, Chrompack [Varian-Chrompack, Middelburg, The Netherlands]). Elution was performed with a gradient of pure ACN (solvent B) in $0.1 \%$ acetic acid (in milliQ water) as follows: (time in $\mathrm{min} / \%$

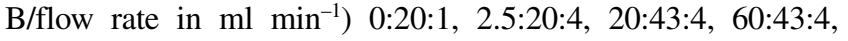
61:95:4, 66:95:4, 67:20:4, and 73:20:4. Samples were monitored spectrophotometrically at $280 \mathrm{~nm}$ and 2-ml samples were collected automatically over the entire run time. Fractions containing peaks of interest were pooled and evaporated in a Speed Vac concentrator SC100 (Savant, Global Medical Instrumentation, Inc., Ramsay, MN, U.S.A.). The pure elicitor was conserved in this lyophilized form at $-20^{\circ} \mathrm{C}$ until use. The compound was collected from multiple HPLC runs to yield approximately $5 \mathrm{mg}$ of pure material. This material was used for ISR bioassays and for structural characterization, and also served to relate HPLC peak areas to absolute amounts determined by weighing the pure powder.

\section{Quantification of elicitor and pyoverdine produced by the strains.}

Bacterial cell densities obtained at the end of the cultures were determined by measuring the optical density at $540 \mathrm{~nm}$, knowing that a value of 1 corresponds to $4.5 \times 10^{8} \mathrm{CFU} \mathrm{ml}{ }^{-1}$. BTP1 pyoverdine concentrations in the cell-free supernatants were calculated on the basis of the absorbance at $400 \mathrm{~nm}$ using a specific molar extinction coefficient $\left(\varepsilon_{400 \mathrm{~nm}, \mathrm{pH}}\right)$ of $2.7510^{4}$ mol liter ${ }^{-1} \mathrm{~cm}^{-1}$ (Jacques et al. 1995).

Elicitor production by the different strains was determined from 10-ml samples of culture supernatant collected after growth for $72 \mathrm{~h}$ in the CAA medium. Supernatant samples were loaded on small C18 solid-phase extraction cartridges $(900 \mathrm{mg}$; Alltech) after activation and conditioning of the cartridge by flushing with $5 \mathrm{ml}$ of $\mathrm{ACN}$ and $10 \mathrm{ml}$ of water. After loading, the packing bed was washed successively with $10 \mathrm{ml}$ of water and $5 \mathrm{ml}$ of $40 \%$ ACN. The remaining material containing the

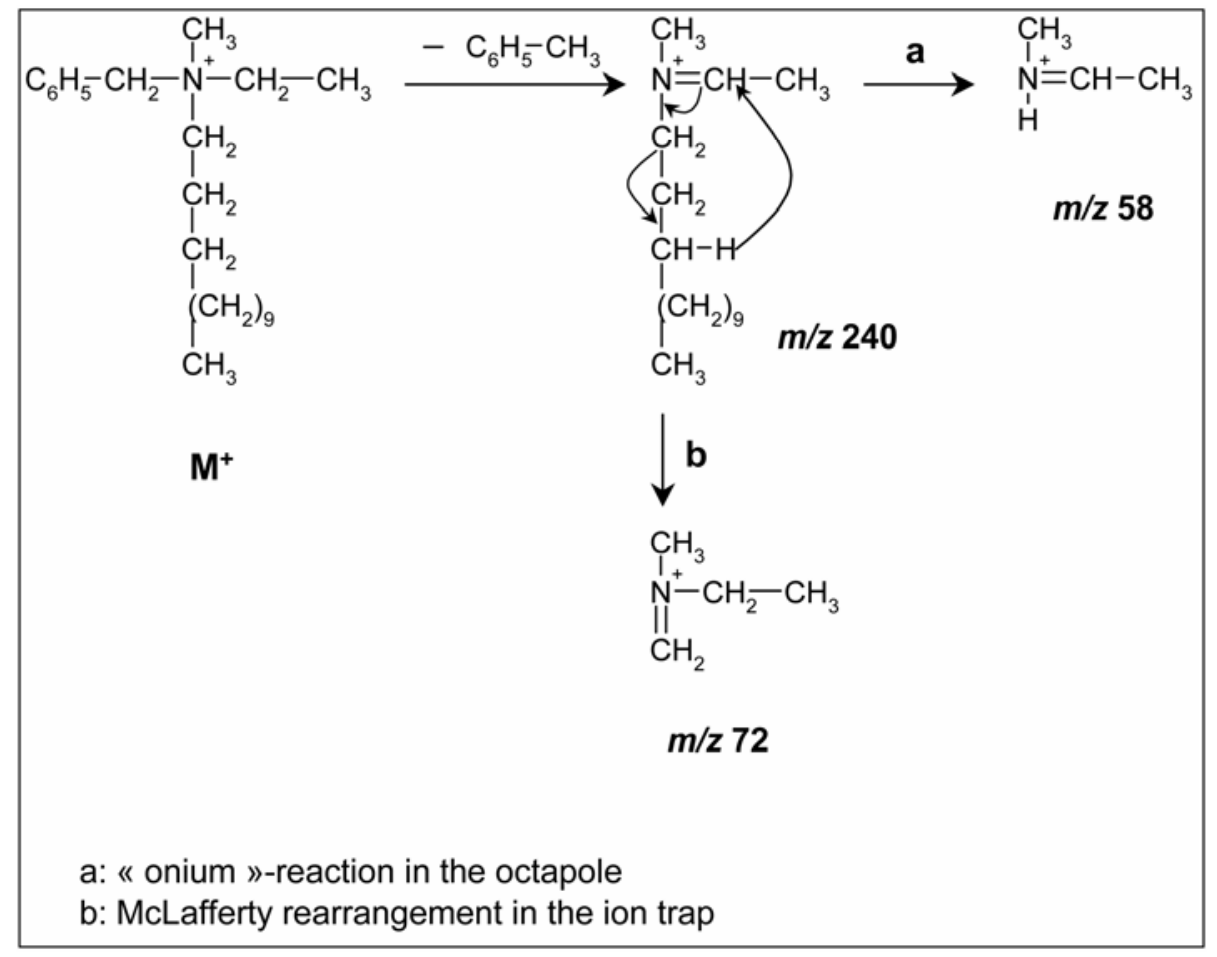

Fig. 5. Intramolecular reactions generating the major fragments observed upon electrospray ionization-mass spectrometry analysis of the induced systemic resistance elicitor from Pseudomonas putida BTP1 $\left(\mathrm{M}^{+}\right)$. 
elicitor then was desorbed with $2 \mathrm{ml}$ of $100 \%$ CAN and evaporated to dryness in a Speed Vac apparatus, and the residue was resolubilized in $80 \mu \mathrm{l}$ of methanol. This solution $(50 \mu \mathrm{l})$ was analyzed by reversed-phase HPLC (HP 1100 series system) on a LiChrospher 100 RP C-18 column ( 250 by $4.6 \mathrm{~mm}, 5-\mu \mathrm{m}$ packing; Merck, Darmstadt, Germany) using the same solvent system as described above and at a constant flow rate of $1 \mathrm{ml} / \mathrm{min}$. The molecule of interest was eluted with a gradient of acetonitrile as follows: (time in $\mathrm{min} / \%$ acetonitrile) 0:20, 2.5:20, 20:47, 60:47, 61:95, and 65:95. Amounts were calculated on the basis of the corresponding peak area at $280 \mathrm{~nm}$.

\section{Assays for induced resistance with bacteria.}

ISR assays were performed with bean (Phaseolus vulgaris) cv. Prelude following the method described by Ongena and associates (2002). Briefly, sterilized seed were dipped for $10 \mathrm{~min}$ in the bacterial suspension at a concentration of $4 \times 10^{8} \mathrm{CFU} / \mathrm{ml}$ prior to sowing. Bean plants then were grown in potting soil previously mixed with BTP1, M1, or M3 cells to a final concentration of $3 \times 10^{7} \mathrm{CFU} / \mathrm{g}$. Additionally, $20 \mathrm{ml}$ of a bacterial suspension at $10^{8} \mathrm{CFU} / \mathrm{ml}$ was added as a drench to the roots of each plant, 7 days after sowing. For control plants, seed were soaked for $10 \mathrm{~min}$ in $\mathrm{NaCl} 0.85 \%$ prior to sowing and 7-day-old bean plants were watered with $20 \mathrm{ml}$ of the same solution. After approximately 20 days, plants were transferred to a high-humidity chamber $\left(19 \pm 2^{\circ} \mathrm{C}\right)$ for $24 \mathrm{~h}$ before leaf infection with $B$. cinerea. This was achieved by inoculating each primary leaf with eight $7-\mu$ drops of a suspension at $5 \times 10^{6}$ spores $/ \mathrm{ml}$ prepared as described (Ongena et al. 2002). Disease incidence was scored every day and was expressed in terms of the percentage of $B$. cinerea lesions that clearly grew out of the inoculum drop zone to produce spreading lesions. Experiments contained 15 plants per treatment and were repeated three times with each bacterial isolate. For disease reduction evaluation, the homogeneity of variances was tested by analysis of variance and data from experiments with the same set-up were pooled for analysis when interaction between experiment and treatment was not significant at $P=0.05$. Means from the different treatments were compared by the method of Newman and Keuls (least significant difference at $\alpha=0.05$; Statistica software).

\section{Assays for induced resistance with supernatant samples and purified elicitor.}

These assays were realized with bean plants grown under hydroponic conditions as described previously (Ongena et al. 2002). Sterilized seed were germinated in perlite and 1-weekold seedlings were removed carefully and transferred to test tubes previously filled with $45 \mathrm{ml}$ of nutrient solution. Six days after transfer, plants were treated by adding $1 \mathrm{ml}$ of either a methanolic solution of material extracted with ethyl acetate from various culture supernatants (SE) or a methanolic solution of the pure elicitor at a final concentration of $0.2 \mu \mathrm{M}$ in the nutrient solution (established after weighing the purified compound and on the basis of the molecular weight determined). SE samples were prepared from lyophilized material corresponding to $300 \mathrm{ml}$ of cell-free culture fluid. The resulting powder was resuspended in $20 \mathrm{ml}$ of distilled water and the solution was adjusted to $\mathrm{pH} 6.5$ with $0.05 \mathrm{M} \mathrm{HCl}$ before extraction with ethyl acetate as described above. The residue was solubilized in an adequate volume of 50\% methanol. Elicitor-depleted SE samples were prepared by submitting ethyl acetate extracts to semi-preparative HPLC. Fractions collected all over the runs except the one containing the elicitor were pooled and the resulting solution was lyophilized and the residue resolubilized in 50\% methanol so as to test the remaining constituents at the same concentration as the elicitor. In all cases, control plants were treated with $1 \mathrm{ml}$ of pure methanol. The volume of nutrient solution in the tubes was adjusted daily with sterile distilled water during the experimental time. Approximately 14 days after treatment, plants were placed in the high-humidity chamber and infected with the pathogen $B$. cinerea as mentioned above, except that six infection sites were created on each first leaf. In every experiment, 20 plants were used per treatment and disease reductions were calculated from results obtained in two independent experiments.

\section{Mass spectrometry analyses.}

Mass spectrometry investigations of the elicitor were performed with a Finnigan-MAT 900ST instrument equipped with an electrospray ion source (ESI-MS). Collision activation of mass-selected ions was performed either in the octapole region or in the ion trap. In the octapole, consecutive fragmentation processes are possible; whereas, in the ion trap, all fragments must stem from the selected precursor ion. Samples were dissolved in $\mathrm{CH}_{3} \mathrm{OD}$.

\section{Chemical synthesis.}

The first two steps for the synthesis of quaternary ammonium starting from phenylethylamine were realized based on the methodology described by Salvatore and associates (2002) with few adaptations. The use of $\mathrm{CsOH}$ ensured a highly chemoselective reaction favoring mono- $\mathrm{N}$-alkylation of the primary amine over dialkylation. Typically, 1-bromodecane (1.2 equivalent) was added to anhydrous N,N-dimethylformamide containing phenylethylamine (1 equivalent), cesium hydroxide monohydrate ( 2 equivalent), and activated powdered molecular sieves. The reaction was allowed to proceed for $48 \mathrm{~h}$ at room temperature and yielded mostly $N$-decyl-phenylethylamine (89\%) compared with polyalkylated products. The desired secondary amine was purified from the crude mixture as described, with final precipitation obtained by adding ethyl acetate and incubating overnight at $0^{\circ} \mathrm{C}$. Purity and structure of this first synthetic intermediate were confirmed by ESI-MS and nuclear magnetic resonance (data not shown). The second step leading to the $N$-decyl$\mathrm{N}$-butyl intermediate was performed in the same way (addition of 1-bromobutane), except that $\mathrm{CsOH}$ was not added in excess. This reaction yielded almost exclusively the expected product (98\%), which was further purified using the same procedure. The $N$-decyl- $N$-butyl-phenylethylamine served as substrate from the last methylation step, which resulted from an acido-basic reaction performed as follows. The tertiary amine $(200 \mathrm{mg}, 1$ equivalent) was dissolved in $2 \mathrm{ml}$ of anhydrous diethyl ether under inert atmosphere. Methyl-trifluoromethanesulfonate (350 $\mathrm{mg}, 1.75$ equivalent) was added to the solution and the resulting mixture was stirred at $0^{\circ} \mathrm{C}$ for $2 \mathrm{~h}$ until the formation of a white precipitate. This precipitate, containing the expected quaternary ammonium salt in an almost pure form $(94.7 \%$ as estimated by mass spectrometry), was recovered by filtration, washed successively with $3 \mathrm{ml}$ of cold dichloromethane and the same volume of cold diethyl ether, and dried in vacuo. Synthesis of $N$-alkyl derivative starting from benzylamine strictly followed the procedure described above, with the exception that $\mathrm{CsOH}$ was not added in excess.

\section{ACKNOWLEDGMENTS}

This work received financial support from the Program F.R.F.C. no. 2.4.570.00 (National Funds for Scientific Research, F.N.R.S., Belgium), and E. Jourdan is a recipient of a grant from the Formation à la Recherche dans l'Industrie et l'Agriculture (F.R.I.A.).

\section{LITERATURE CITED}

Audenaert, K., Pattery, T., Cornelis, P., and Höfte, M. 2002. Induction of systemic resistance to Botrytis cinerea in tomato by Pseudomonas aeruginosa 7NSK2: Role of salicylic acid, pyochelin and pyocyanin. 
Mol. Plant-Microbe Interact. 15:1147-1156.

Budzikiewicz, H. 2004. Siderophores of the Pseudomonadaceae sensu stricto (fluorescent and non-fluorescent Pseudomonas spp.). Prog. Chem. Org. Nat. Prod. 87:81-237.

Cornelis, P., Anjaiah, V., Koedam, N., Delfosse, P., Jacques, P., Thonart, P., and Neirinckx, L. 1992. Stability, frequency, and multiplicity of transposon insertions in the pyoverdine region in the chromosome of different fluorescent pseudomonads. J. Gen. Microbiol. 138:1337-1343.

De Meyer, G., and Höfte, M. 1997. Salicylic acid produced by the rhizobacterium Pseudomonas aeruginosa 7NSK2 induces resistance to leaf infection by Botrytis cinerea on bean. Phytopathology 87:588-593.

De Meyer, G., Capieau, K., Audenaert, K., Buchala, A., Métraux, J. P., and Höfte, M. 1999. Nanogram amounts of salicylic acid produced by the rhizobacterium Pseudomonas aeruginosa 7NSK2 activate the systemic acquired resistance pathway in bean. Mol. Plant-Microbe Interact. $12: 450-458$

Duijff, B. J., Gianinazzi-Pearson, V., and Lemanceau, P. 1997. Involvement of the outer-membrane lipopolysaccharides in the endophytic colonization of tomato roots by biocontrol Pseudomonas fluorescens WCS417r. New Phytol. 135:325-334.

Durrant, W. E., and Dong, X. 2004. Systemic acquired resistance. Annu. Rev. Phytopathol. 42:185-209.

Ebel, J., and Mithofer, A. 1998. Early events in the elicitation of plant defence. Planta 206:335-348.

Fliegmann, J., Schuler, G., Boland, W., Ebel, J., and Mithofer, A. 2003 The role of octadecanoids and functional mimics in soybean defense responses. Biol. Chem. 384:437-446.

Haas, D., and Keel, C. 2003. Regulation of antibiotic production in rootcolonizing Pseudomonas spp. and relevance for biological control of plant disease. Annu. Rev. Phytopathol. 41:117-153.

Hammerschmidt, R. 1999. Phytoalexins: What have we learned after 60 years? Annu. Rev. Phytopathol. 37:285-306.

Jacques, P., Ongena, M., Gwose, I., Seinsche, D., Schröder, H., Delfosse, P., Thonart, P., Taraz, K., and Budzikiewicz, H. 1995. Structure and characterization of isopyoverdin from Pseudomonas putida BTP1 and its relation to the biogenetic pathway leading to pyoverdines. $\mathrm{Z}$. Naturforsch. (C) 50:622-629.

Klarzynski, O., Descamps, V., Plesse, B., Yvin, J. C., Kloareg, B., and Fritig, B. 2003. Sulfated fucan oligosaccharides elicit defense responses in tobacco and local and systemic resistance against tobacco mosaic virus. Mol. Plant-Microbe Interact. 16:115-122.

Kloepper, J. W., Tuzun, S., and Kuć, J. A. 1992. Proposed definitions related to induced disease resistance. Biocontrol Sci. Technol. 2:349-351.

Kuć, J. 2001. Concepts and direction of induced systemic resistance in plants and its application. Eur. J. Plant Pathol. 107:7-12.

Lavicoli, A., Boutet, E., Buchala, A., and Métraux, J. P. 2003. Induced systemic resistance in Arabidopsis thaliana in response to root inoculation with Pseudomonas fluorescens CHA0. Mol. Plant-Microbe Interact. 16:851-858.

Leeman, M., van Pelt, J. A., den Ouden, F. M., Heinsbrock, M., Bakker, P. A. H. M., and Schippers, B. 1995. Induction of systemic resistance against Fusarium wilt of radish by lipopolysaccharides of Pseudomonas fluorescens. Phytopathology 85:1021-1027.

Leeman, M., den Ouden, F. M., van Pelt, J. A., Dirkx, F. P. M., Steijl, H., Bakker, P. H. A. M., and Schippers, B. 1996. Iron availability affects induction of systemic resistance to Fusarium wilt of radish by Pseudomonas fluorescens. Phytopathology 86:149-155.

Loper, J. E., and Buyer, J. S. 1991. Siderophores in microbial interactions on plant surfaces. Mol. Plant-Microbe Interact. 4:5-13.

Maurhofer, M., Hase, C., Meuwly, P., Métraux, J. P., and Défago, G. 1994. Induction of systemic resistance of tobacco to tobacco necrosis virus by the root-colonizing Pseudomonas fluorescens strain CHA0: Influence of the gacA gene and of pyoverdine production. Phytopathology 84:139-146.

Maurhofer, M., Reimmann, C., Schmidli-Sacherer, P., Heeb, S., Haas, D., and Defago, G. 1998. Salicylic acid biosynthetic genes expressed in Pseudomonas fluorescens strain P3 improve the induction of systemic resistance in tobacco against tobacco necrosis virus. Phytopathology 88:678-684

Mercado-Blanco, J., van der Drift, K., Olsson, P. E., Thomas-Oates, J. E., van Loon, L. C., and Bakker, P. 2001. Analysis of the pmsCEAB gene cluster involved in biosynthesis of salicylic acid and the siderophore pseudomonine in the biocontrol strain Pseudomonas fluorescens WCS374. J. Bacteriol. 183:1909-1920.

Nürnberger, T., and Scheel, D. 2001. Signal transmission in the plant immune response. Trends Plant Sci. 6:372-379.

Ongena, M., Daayf, F., Jacques, P., Thonart, P., Benhamou, N., Paulitz, T. C., Cornélis, P., Koedam, N., and Bélanger, R. R. 1999. Protection of cucumber against Pythium root rot by fluorescent pseudomonads: Pre- dominant role of induced resistance over siderophores and antibiosis. Plant Pathol. 48:66-76.

Ongena, M., Daayf, F., Jacques, P., Thonart, P., Benhamou, N., Paulitz, T. C., and Bélanger, R. R. 2000. Systemic induction of phytoalexins in cucumber in response to treatments with fluorescent pseudomonads. Plant Pathol. 49:523-530.

Ongena, M., Jacques, P., Delfosse, P., and Thonart, P. 2001. Unusual traits of the pyoverdin-mediated iron acquisition system in Pseudomonas putida strain BTP1. Biometals 15:1-13.

Ongena, M., Giger, A., Jacques, P., Dommes, J., and Thonart, P. 2002. Study of bacterial determinants involved in the induction of systemic resistance in bean by Pseudomonas putida BTP1. Eur. J. Plant Pathol. 108:187-196.

Oostendorp, M., Kunz, W., Dietrich, B., and Staub, T. 2001. Induced disease resistance in plants by chemicals. Eur. J. Plant Pathol. 107:19-28.

Press, C. M., Wilson, M., Tuzun, S., and Kloepper, J. W. 1997. Salicylic acid produced by Serratia marcescens $90-166$ is not the primary determinant of induced systemic resistance in cucumber or tobacco. Mol. Plant-Microbe Interact. 10:761-768.

Press, C. M., Loper, J. E., and Kloepper, J. W. 2001. Role of iron in rhizobacteria-mediated induced systemic resistance of cucumber Phytopathology 91:593-598.

Raaijmakers, J. M., Leeman, M., van Oorschot, M. M. P., van der Sluis, I. Schippers, B., and Bakker, P. A. H. M. 1995. Dose-response relationships in biological control of Fusarium wilt of radish by Pseudomonas spp. Phytopathology 85:1075-1081.

Raaijmakers, J. M., Vlami, M., and de Souza, J. T. 2002. Antibiotic production by bacterial biocontrol agents. Antonie Leeuwenhoek 81:537-547.

Ramamoorthy, V., Viswanathan, R., Raguchander, T., Prakasam, V., and Samiyappan, R. 2001. Induction of systemic resistance by plant growth promoting rhizobacteria in crop plants against pests and diseases. Crop Prot. 20:1-11.

Reitz, M., Oger, P., Meyer, A., Niehaus, K., Farrand, S. K., Hallmann, J., and Sikora, R. A. 2002. Importance of the O-antigen, core-region and lipid A of rhizobial lipopolysaccharides for the induction of systemic resistance in potato to Globodera pallida. Nematology 4:73-79.

Ryu, C. M., Farag, M. A., Hu, C. H., Reddy, M. S., Kloepper, J. W., and Pare, P. W. 2004. Bacterial volatiles induce systemic resistance in Arabidopsis. Plant Physiol. 134:1017-1026.

Salvatore, R. N., Nagle, A. S., and Jung, K. W. 2002. Cesium effect: High chemoselectivity in direct $\mathrm{N}$-alkylation of amines. J. Org. Chem. 67:674-683.

Serino, L., Reimmann, C., Visca, P., Beyeler, M., Della Chiesa, V., and Haas, D. 1997. Biosynthesis of pyochelin and dihydroaeruginosic acid requires the iron-regulated pchDCBA operon in Pseudomonas aeruginosa. J. Bacteriol. 179:248-257.

Silla Santos, M. H. 1996. Biogenic amines: Their importance in foods. Int J. Food Microbiol. 29:213-231.

Sticher, L., Mauch-Mani, B., and Métraux, J. P. 1997. Systemic acquired resistance. Annu. Rev. Phytopathol. 35:235-270.

Tanaka, N., Che, F. S., Watanabe, N., Fujiwara, S., Takayama, S., and Isogai, A. 2003. Flagellin from an incompatible strain of Acidovorax avenae mediates $\mathrm{H}_{2} \mathrm{O}_{2}$ generation accompanying hypersensitive cell death and expression of PAL, Cht-1, and PBZ1, but not of LOX in rice. Mol. Plant-Microbe Interact. 16:422-428.

Van Loon, L. C., Bakker, P. A. H. M., and Pieterse, C. M. J. 1998. Systemic resistance induced by rhizosphere bacteria. Annu. Rev. Phytopathol. 36:453-483.

Van Peer, R., and Schippers, B. 1992. Lipopolysaccharides of plantgrowth promoting Pseudomonas sp. strain WCS417r induce resistance in carnation to Fusarium wilt. Neth. J. Plant Pathol. 98:129-139.

Walsh, U. F., Morrissey, J. P., and O'Gara, F. 2001. Pseudomonas for biocontrol of phytopathogens: From functional genomics to commercial exploitation. Curr. Opin. Biotechnol. 12:289-295.

Waspï, U., Blanc, D., Winkler, T., Ruedi, P., and Dudler, R. 1998. Syringolin, a novel peptide elicitor from Pseudomonas syringae pv. syringae that induces resistance to Pyricularia oryzae in rice. Mol. PlantMicrobe Interact. 11:727-733.

Wei, G., Kloepper, J. W., and Tuzun, S. 1996. Induced systemic resistance to cucumber diseases and increased plant growth by plant growth-promoting rhizobacteria under field conditions. Phytopathology 86:221-224.

Whipps, J. M. 2001. Microbial interactions and biocontrol in the rhizosphere. J. Exp. Bot. 52:487-511.

Zahir, Z. A., Arshad, M., and Frankenberger, W. T. 2004. Plant growth promoting rhizobacteria: Applications and perspectives in agriculture. Adv. Agron. 81:97-168

Zehnder, G. W., Murphy, J. F., Sikora, E. J., and Kloepper, J. W. 2001. Application of rhizobacteria for induced resistance. Eur. J. Plant Pathol. 107:39-50. 